\title{
HOW MANY WAYS TO DEAL WITH STRESS? STRESS COPING FACTORS IN THE SVF 78
}

\author{
Karel Balcar, ${ }^{*}$ Radek Trnka, Martin Kuška \\ Science and Research Department, Prague College of Psychosocial Studies, Prague, Czech Republic
}

\begin{abstract}
Coping strategies belong undoubtedly to the most relevant variables for human performance and health. The Stress Coping Style Questionnaire SVF 78 has previously received critical remarks for the lack of theoretical foundations and unclear interrelationships between included strategies of coping. The present study verifies the factor structure of SVF 78 using exploratory factor analysis in a sample of 187 Czech undergraduates. Four common factors were extracted, interpreted and compared with the 3and 5-factor solutions of the same data and with other studies analyzing local versions of the SVF Questionnaire in other countries. The results support methodological usefulness of using common factor scores instead of only empirically constructed stress coping questionnaire scales, particularly for research purposes.
\end{abstract}

Key words: stress coping; coping styles; factor analysis; SVF Questionnaire

\section{INTRODUCTION}

"Stress" has become a rallying cry of the modern psychology and psychosomatics. The antidote against its presumably destructive powers is called "coping". Coping denotes the psychological operations, both conscious and non-conscious, that a person applies to manage the demands of a stressful situation or event. The coping operations comprise cognitive, emotional, behavioral and physiological processes actualized in various combinations that are selectively and purposively effective in alleviating the person's acute or chronic overload with the demands he or she is not able to master at the time using only his or her habitual skills (cf. Cohen et al., 1995). Consequently, regardless of the original nature of the stressor (the "thing that interferes with an important personal goal" - Rubin, Peplau \& Salovey, 1993), the state of overload - the "strain" - always includes as its most remarkable feature intense emotional arousal.

The various ways of coping are first acquired through (mostly non-conscious) learning experiences (Janke \& Erdmannová, 2003, p. 7-8), that are - as any personal traits - modified by the constitutional biological, psychological and social qualities or tendencies in the person. Then, other ways of mastering the stress events may be (consciously) learned and practiced to be applied either voluntarily or habitually for better results. It is not feasible for a person to deliberately choose his or her coping response to each one of the stress situation encountered. Therefore, the ways of coping elicited have a tendency to be repeated and to acquire the nature of a habitual response or strategy - that of a "coping style", that becomes part of his or

*Correspondence to: Karel Balcar, PVSPS, Hekrova 25, 14900 Praha 4, Czech Republic. E-mail:vyzkum@pvsps.cz Received November 5, 2010; accepted December 6, 2010; Act Nerv Super (Praha) 53(1-2), 27-34. 
her personality structure and is conceived as a trait (Lazarus, 2006, 103-110). Different persons have different degrees of inclination toward different styles of coping that are shared within the human species generally and within the particular culture in particular. Some of the styles prove to be more and other ones less beneficial either in general or with regard to different circumstances.

As both the clinical and theoretical knowledge shows, the stress-coping strategies belong undoubtedly to the most relevant variables for human performance and health (Rubin, Paplau, \& Salovey, 1993; for a very representative review see Adler et al., 2003). Therefore, also the efforts to map them and to assess their prevalence led to the construction of quite a few diagnostic instruments that rely mostly on the subject's reporting his or her habitual reactions to stressful events. Out of them, only the Stress Coping Style Questionnaire SVF 78 is standardized for the Czech cultural background (Janke \& Erdmannová, 2003). Its construction is based on some very general theoretical assumptions:

1. The changes in a person's state under stress are active responses aimed at restoring the foregoing psychological a somatic state of equilibrium.

2. The ways a person reacts to stress are conceived as habitual personality traits that are stable across time ("time constancy").

3. The ways of a particular person's responding to stress are relatively independent of the kind of the stress situation ("situation constancy").

4. The ways a particular person uses while coping with stress are relatively independent of his or her kind of specific reaction elicited by the stress ("reaction constancy").

5. Using correlational analysis it is possible to distinguish a number of relatively mutually independent was of coping with stress ("multidimensionality").

6. The stress-coping styles used are not predetermined in any decisive manner by other personality characteristics.

7. As a questionnaire, the SVF assumes that a person is aware of his or her stress-coping strategies to the extent that it is possible to ask him or her using verbal techniques.

As to its contents, the coping styles assessed with the particular propositions are not theoryderived but rather inductively assembled using people's descriptions, categorization, and item-analysis. Therefore, this questionnaire has previously received critical remarks for the lack of specific theoretical foundations and unclear interrelationships between included strategies of coping (e.g., Krohne, 1996, p. 385). Therefore, the reassessment of the factor structure seems to be desirable for the current discussion. The present study aims at verifying the factor structure of SVF 78 in the Czech milieu.

There seems to be a gap between what people do and what the stress coping theory predicts, namely, the two hyper-strategies of "problem-focused" and "emotion-focused" coping (Lazarus, 1999, pp. 114-116). Building a two-way bridge between theory and observation in this case involves, on the one hand, constructing theory-derived psychometric instruments, and on the other hand, searching for the theory-predicted concepts via factor analysis of the empirically constructed stress-coping scales. To contribute to this endeavor is also the goal of the present study.

Nowadays, not many psychometrists would endorse R. B. Cattell's half a century old radical dictum: "Factors [to be discovered by factor analysis] are influences" (e.g., Cattell, 1965, p. 369). It is generally preferred to call factor analysis just a "data reduction" technique. Nevertheless, we may suppose that there is a set of relatively independent influences at work in producing observed or reported stress coping reactions in people. A sound factor analytical procedure may, therefore, well be expected to arrive at factor solutions actually reflecting their nature and interrelations.

The following analysis contributes to such efforts to detect empirically and mathematically well founded links between theory and observation, using factor analysis of "observables" to support or to dispute theoretical expectations. To this, we undertook a factor analytic study of the internationally recognized stress-coping styles measure indicated. This enables us to obtain a particular factor resolution reflecting the structure of psychological agents affecting 
the various ways of coping in our sample, and to compare it as well with analogous results arrived at in similar investigations abroad.

\section{METHOD}

The Czech version of the German Stress Coping Style Questionnaire SVF 78 (Janke \& Erdmannová, 2003; Janke \& Erdmann, 2002) was administered to 187 undergraduate students. The sample consisted of 85 males and 102 females in the age range 19 to 34 years, with a mean of 22.6 and a standard deviation of 3.2.

The questionnaire consists of 78 items, each completing the common introductory sentence: "When I have been upset by anybody, disturbed by anything, or somehow thrown off balance, ...", with a preprinted predicate, e.g., "... I tell myself, "It is not that bad"." The respondent evaluates each assertion as it applies to him/herself according to the probability of that reaction, using a 5-point scale, ranging from "Not at all" to "Very likely".

The 78 items are grouped by 6 to make up 13 scales, each representing a particular way of reacting to a stressful event: Play down, Guilt denial, Substitutional satisfaction, Situation control, Reaction control, Positive self-instruction, Need for social support, Active avoidance, Flight tendency, Rumination, Resignation, Self-accusation. The internal consistencies of individual scales in the Czech standardization intervene between 0.77 and 0.94 Cronbach alpha.

The scores obtained form a table of 187 by 13 and, as such, they were correlated and processed utilizing the SPSS 14.0 (2005) Factor Analysis program with the Direct Oblimin rotation, resulting in a factor pattern to be interpreted.

\section{RESULTS}

First, a component analysis revealed the following eigenvalues succession - Table 1 .

Table 1. Principal components extracted

\begin{tabular}{|c|c|c|c|}
\hline \multirow{2}{*}{ Component } & \multicolumn{3}{|c|}{ Initial Eigenvalues } \\
\cline { 2 - 4 } & Total & Variance \% & Cumulative \% \\
\hline 1 & 3.44 & 26.4 & 26.4 \\
\hline 2 & 2.60 & 20.0 & 46.4 \\
\hline 3 & 1.67 & 12.8 & 59.3 \\
\hline 4 & 1.18 & 9.0 & 68.3 \\
\hline 5 & 0.88 & 6.8 & 75.1 \\
\hline 6 & 0.79 & 6.1 & 81.1 \\
\hline 7 & 0.56 & 4.3 & 85.4 \\
\hline 8 & 0.45 & 3.5 & 88.9 \\
\hline 9 & 0.39 & 3.0 & 91.9 \\
\hline 10 & 0.36 & 2.8 & 94.7 \\
\hline 11 & 0.35 & 2.7 & 97.4 \\
\hline 12 & 0.28 & 2.1 & 99.5 \\
\hline 13 & 0.06 & 0.5 & 100.0 \\
\hline
\end{tabular}

Note. Small discrepancies between the individual and cumulative percentage columns are due to rounding. This is also shown in the scree plot obtained - Figure 1. 


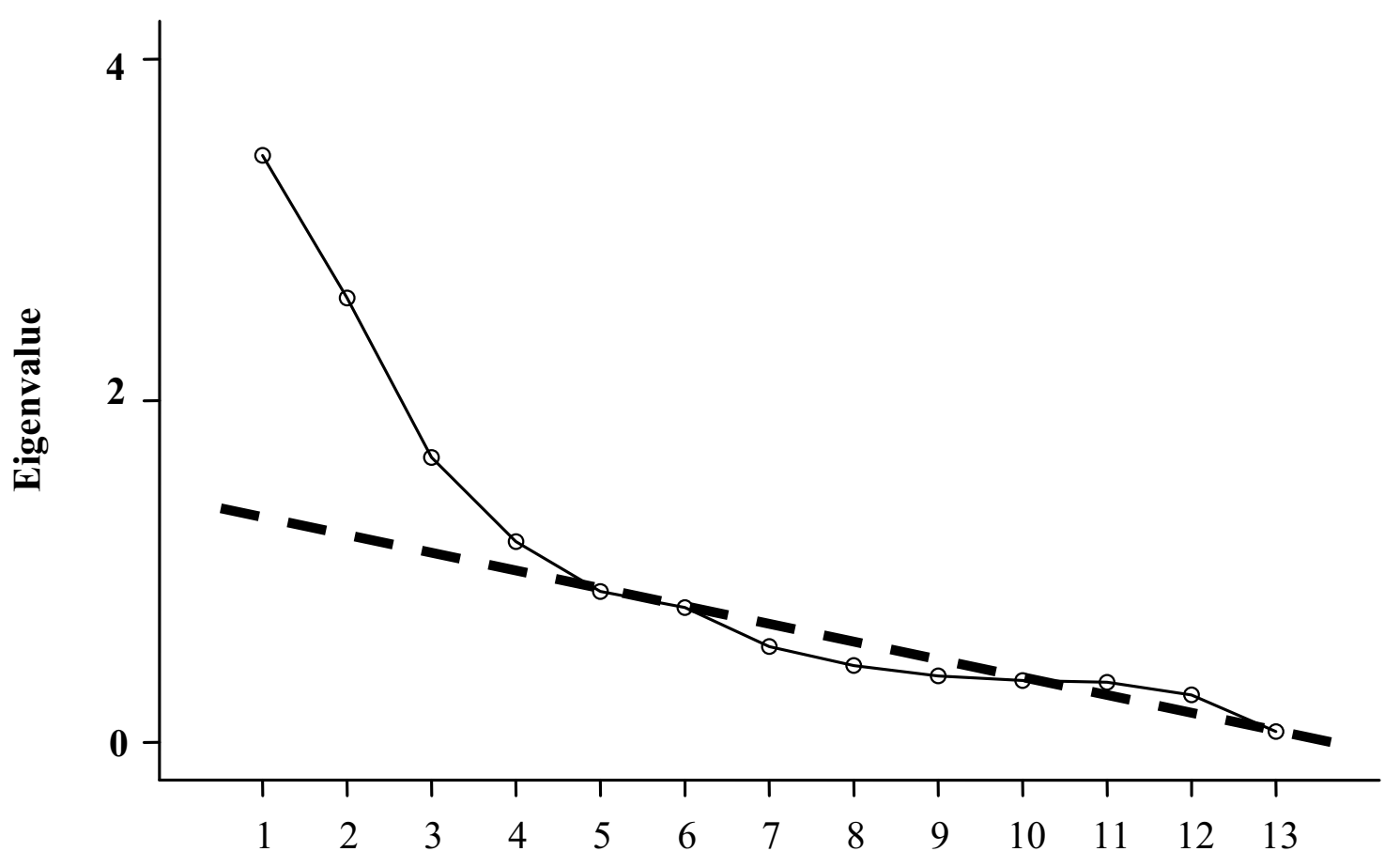

\section{Component Number}

Figure 1. Scree plot with the scree-test line.

Applying both commonly used criteria - Kaiser-Guttman's eigenvalue $>1$, and Cattell's graphical "scree-test" (Guttman, 1955; Kaiser \& Dickman, 1959; Cattell, 1966) as the cut-offs, we arrived at a 4-factor solution as analytically the most suitable one. For comparison purposes, we also performed and interpreted the analyses for 3- and 5-factor solutions as well. Factor pattern matrices of the solutions are shown in the Table 2. For interpretation and comparison purposes, we take into account only the loadings exceeding the value of \pm 0.40 , i.e. e., corresponding to at least $16 \%$ of common variance in correlational analysis. We call them "salient loadings" and use them to define the respective factor.

Further, we proceed with the content interpretations of the 4-factor solution:

Factor 1 is marked by salient negative loadings on the scales "Play down" and "Guilt denial", and by salient positive loadings on the scales "Need for social support", "Flight tendency", "Rumination", "Resignation", and "Self-accusation" (the latter four labeled by the SVF authors "negative coping strategies", tending to increase the stress experienced instead of decreasing it).

We interpret this factor accordingly as the "Breakdown of psychological defense" ( or, at its opposite pole, "Effective psychological defense"). The persons scoring high on this factor seem to be unable further on to attenuate the stress experienced by utilizing the defensive "denying" strategies, and tend on the one hand to look up to outer help, on the other one to still more amplify their stress by giving over to the self-torturing activities of wishing to fly away from the situation, by ruminating about the situation, giving up and accusing themselves for its occurrence.

Factor 2 is marked by salient positive loadings on the scales "Situation control", "Reaction control", "Positive self-instruction" and "Active avoidance". 
Table 2. SVF 78: three-, four-, and five factor solutions*

\begin{tabular}{|c|c|c|c|c|c|c|c|c|c|c|c|c|}
\hline \multirow[b]{2}{*}{ SVF 78 scale: } & \multicolumn{3}{|c|}{ 3-f solution: } & \multicolumn{4}{|c|}{ 4-f solution: } & \multicolumn{5}{|c|}{ 5-f sohution: } \\
\hline & F1 & $\mathbf{F} 2$ & F3 & F1 & F2 & F3 & F4 & F1 & F2 & F3 & F4 & F5 \\
\hline Play down &. .75 & & & -.51 & & & 41 & & & 44 & & \\
\hline Guilt deninl & -.56 & & &. .59 & & & & & & & & .99 \\
\hline $\begin{array}{l}\text { Dis traction } \\
\text { from sitution }\end{array}$ & & & 81 & & & 83 & & & & 83 & & \\
\hline $\begin{array}{l}\text { Subs titutional } \\
\text { satis faction } \\
\text { Sitution } \\
\text { control }\end{array}$ & . & .93 & .61 & & .96 & 42 & -.76 & & .96 & 43 & -80 & \\
\hline $\begin{array}{l}\text { Reaction } \\
\text { control }\end{array}$ & & .91 & & & .95 & & & & .95 & & & \\
\hline $\begin{array}{l}\text { Positive self- } \\
\text { instruction }\end{array}$ & & .74 & & & .65 & & & & .64 & & & \\
\hline $\begin{array}{l}\text { Need for } \\
\text { soc. support }\end{array}$ & .58 & & & & & &. .79 & & & & -.79 & \\
\hline $\begin{array}{l}\text { Active } \\
\text { avoidance }\end{array}$ & & & 48 & & 43 & 41 & & & .44 & & & \\
\hline $\begin{array}{l}\text { Flight } \\
\text { tendency }\end{array}$ & & & .58 & .63 & & .54 & & .85 & & & & \\
\hline Rummation & .78 & & & .59 & & & & .58 & & &. .44 & \\
\hline Resignntion & .54 & & & .68 & & & & .83 & & & & \\
\hline $\begin{array}{l}\text { Self- } \\
\text { accusation }\end{array}$ & .70 & & & .79 & & & & .53 & & & &. .45 \\
\hline & & & & & & & & & & & & \\
\hline $\begin{array}{l}\text { Voriance \% } \\
\text { explained: }\end{array}$ & 24 & 32 & 15 & 24 & 21 & 13 & 14 & 22 & 21 & 12 & 14 & 15 \\
\hline
\end{tabular}

* For reading convenience, loadings smaller than 0.40 , i.e., corresponding to less than $16 \%$ of the variance in common, are left out, and the zeros in the loading values presented are omitted.

We interpret this factor accordingly as the "Active problem confrontation". The persons scoring high on this factor seem to attempt to master the situational causes of stress by own voluntary efforts, supporting him/herself with positively motivating self-instructions to it.

Factor 3 is marked by salient positive loadings on the scales "Distraction from the situation", "Flight tendency", "Substitutional satisfaction", and "Avoidance".

We interpret this factor accordingly as the "Active situation avoidance" in both the psychological as well as physical sense. The persons scoring high on this factor seem to attempt to attenuate the stress experience by turning away or fleeing away from the frustrating situation to "safer places" for satisfying their frustrated needs and protecting themselves from eventual perils.

Factor 4 is marked by salient negative loadings on the scales "Substitutional satisfaction", and "Need for social support", and by a salient positive loading on "Play down". 
After reversing the signs of its loadings for easier comprehension, we interpret this factor accordingly as the "Psychological compensation". The persons scoring high on this factor seem to attempt to attenuate the stress experience by turning to others or to surrogate resources for satisfying their frustrated needs, markedly lacking the capacity to defensively minimize the impact of the situation by "playing down" its seriousness.

\section{DISCUSSION}

Comparison with other attempted solutions

Factor 1 in the 3-factor solution is, in its pattern of salients, almost identical with that in the 4factor solution "Breakdown of psychological defenses". In the former, still the "Need for social support" is loaded by it, which in the latter one this "moves" to the Factor 4 "Psychological compensation" as one of its salient constituents. In the 5-factor solution, the psychological defenses of "Playing down" and "Guilt denial" fade away to contribute to other factors, leaving the Factor 1 therein a pure "Negative coping styles" factor.

Factor 2 in all the solutions contains its "Active problem confrontation" triad of "Situation control", "Reaction control", and "Positive self-instructions", combined with the "Active avoidance" in the 4- and 5-factor solutions. In the 3-factor solution, the "Active avoidance" does not reach our limit of salience and contributes to the next factor only.

Factor 3 is in its pattern of salient loadings fully identical in the 3- and 4-factor solutions in its "Active situation avoidance" meaning. In the 5-factor solution, it is only partially reproduced in the form of rather an "Active psychological situation avoidance" factor, with somewhat diminished loadings of the "Active avoidance" and "Flight tendency" (0.39 and 0.27 respectively) that already fall somewhat bellow our cut-off salience value.

Factor 4 interpreted here as "Psychological compensation" is in the 4-factor solution an additional factor comparing to the 3 factor solution, and is partially reproduced as factor 4 in the 5 -factor solution. Therein, the lack of the "Play down" strategy looses its salience dropping to 0,38 , leaving as salients only the "compensatory" strategies of turning to need satisfaction either to substitutes or to others.

Factor 5 appearing, naturally, only in the 5 -factor solution, is in this case a clear "Guilt defense" factor, loading positively the "Guilt denial" and negatively the "Self-accusation" scales. These loadings contribute in the 3- and 4-factor solutions (and the "Self-accusation" in the 5-factor solution as well) already to the most robust Factor 1 "Breakdown of psychological defense". Its appearance in this solution suggests relative discreteness of the combined guilt denying and guilt self-attributing apart from other psychological defensive strategies.

It is evident that in all the factor resolutions examined the factor composition is fairly similar which gives credibility to eventual conclusions deduced therefrom. Looking for the theoretically traditional search for the "Problem-focused" versus "Emotion-focused" coping strategies, the empirically derived factors present a somewhat more complicated but generally not incompatible structure. This may be shown on the preferred 4 -factor solution.

The "Problem-focused coping" has its counterpart in the Factor 2 "Active problem confrontation", wherein the "Situation control" and "Reaction control" loadings are the markers by exceeding the value of 0.90 , and the other two salients, "Positive selfinstructions" and "Active avoidance" may be well conceived of as eventual parts of the problem solution.

On the other hand, the "Emotion-focused coping" fills most of the remaining factors. In its purest form, it may be seen in the Factor 1 "Breakdown of psychological defense" (or, at its polar quality, "Effective psychological defense").

The remaining two factors, Factor 3 "Active situation avoidance" and Factor 4 "Psychological compensation" may possibly be regarded as mixtures of both Problem-focused and Emotionfocused ones. Whereas the "Distraction (of attention)", "Play down (the problem)" and the "Flight tendency" seem to be rather "emotion-focused", the "Active avoidance" may be seen 
(at least in some situations) as an attempt at problem solving. The "Substitutional satisfaction" as well as "Need for social support" may serve both aims, depending on the nature of the frustration or threat encountered.

To the general composition of the set of "stress coping styles" in the SVF 78 it may be critically commented, in accord with the previously brought in critique on the lack of theoretical foundations, leading to the fact that the interrelationships between these coping strategies often remain unclear and, occasionally, they may form not real alternatives but a chain of interdependent reactions displayed subsequently at distinct time points during a stressful encounter. The structure of factors found in our study does, to some extent, support this critique. At the same time, in terms of the factors defined, it may offer a bridging alternative sought for.

Stress coping factors in other SVF studies

The SVF 78 is an abbreviated version of the SVF 120 (Janke, Erdmann, \& Kallus, 1985) which included 6 more coping style scales. Factor analyses of the SVF were performed on both versions.

Busjahn et al. (1999) in their SVF 120 study extracted 6 common factors. However, on psychometric grounds, they also chose only the 4-factor solution for interpretation. They arrived at the following factors: 1 "Defense", 2 "Emotional coping", 3 "Substitution", and 4 "Active coping", that are rather consistent with the factors found in the present study.

Both Weyers et al. (2005) analyzing the SVF 120, and Janke \& Erdmann (2002) analyzing the SVF 78 arrived at 5 distinct coping style factors. According to the SVF 78 study, there is fair although not perfect agreement between most of their factors and the factors found in the present study. Their Factors I and III together are a clear counterpart to our Factor 1 "Breakdown of psychological defense"; their Factor II corresponds to our Factor 2 "Active problem confrontation". Some dissimilarity, however, shows between their remaining Factors IV and V and our Factors 3 "Active situation avoidance" and 4 "Psychological compensation", which is to be attributed to the psychological characteristics of the samples compared.

Finally, the principal component analysis of the SVF reported by Krohne (1996, p. 385) yielded three well-defined factors, while three additional factors referred to less circumscribed areas. The three main factors could be interpreted as "Emotional distress and resignation", "Active control attempts", and "Cognitively avoidant reappraisal". It may be noted that the factor interpretations mentioned fit very closely with the factors of "Breakdown of psychological defense", "Active problem confrontation", and "Active situation avoidance" respectively that were found in the present study.

The present factor analytical study conducted for the first time with the SVF 78 stress coping style scales in a Czech sample shows from good to moderate agreement with earlier analyses performed on other versions of this instrument in other studies. This supports the credibility of the results obtained and, at the same time, allows for taking into account some differences concerning scale interrelations in our sample.

Uses of the SVF 78 questionnaire

Both our analyses and the clinical experience accumulated with the Czech version of the SVF 78 supports the usefulness of this method also in various fields of psychological assessment practice where the coping with stress is an issue. The individual person's scale profile comparative interpretation may show his or her particular stress-coping strengths and risks as far as the self-disclosure in the answers provided is valid. This is usually the case in situations where conscientious cooperation in responding is not burdened with a threat to the subject, that may occur in (not recommended) uses of the questionnaire in, e.g., personal selection procedures. There is no control scale to assess the degree of the social desirability tendency taking effect in the testing under such circumstances. In counseling or therapy settings, the original scale-based scores display sufficient credibility and usefulness for diagnostic purposes, although due to their conceptual promiscuity they do not allow for a 
causal dynamic interpretation - this is to be completed by a clinically oriented exploration. The T-score norms published in the Czech manual are thus adapted from abroad studies and call for confirmation, although there is no reason to doubt their general transferability within the Mid-European cultural milieu.

On the other hand, we are aware of limitations to using just short individual questionnaire scales for personality and stress research purposes. For this we recommend, based on our own results as well as on those of other investigators' analyses, to use factor scores from one of our factor solutions presented in this study as more reliable and theoretically better interpretable variables. The choice preferred on the factor analytical grounds is that of the four-factor solution. However, as to the theoretical grounds and purpose of the eventual study, also the 3- or 5-factor solutions may show of advantage. Such application of the results obtained in this study is desirable at least in theoretical research, though not necessarily in psychological practice.

\section{ACKNOWLEDGEMENT}

This study was supported by Czech Science Foundation 406/09/0294 “Coping strategies and emotional meaning space".

\section{REFERENCES}

Adler, R. H., Herrmann, J. M., Köhle, K., Langewitz, W., Schonecke, O. W., Uexküll, T. von, \& Wesiack, W. (2003). Uexküll Psychosomatische Medizin. (6. Aufl.) München: Urban \& Fischer.

Busjahn, A., Faulhaber, H.-D., Freier, K. \& Luft, F. C. (1999). Genetic and environmental influences on coping styles: A twin study. Psychosomatic Medicine, 61, 469-475.

Cattell, R. B. (1965). The scientific analysis of personality. Chicago: Aldine.

Cattell, R. B. (1966). The scree test for the number of factors. Multivariate Behavioral Research, 1, 245.

Chang, E., \& Strung, D. R. (1999). Dysphoria: Relations to appraisals, coping, and adjustment. Journal of Counseling Psychology, 46, 99-108.

Cohen, S., Kessler, R. C., \& Gordon, L. U. (1995). Strategies for measuring stress in studies of psychiatric and physical disorders. In Cohen, S., Kessler, R. C., \& Gorden, L. U. (Eds). Measuring stress. A guide for health and social scientists. Oxford: Oxford University Press.

Guttman, L. (1955). Some necessary conditions for common factor analysis. Psychometrika, 19, 149-161.

Janke, W., Erdmann, G., \& Kallus, W. (1985). Stressverarbeitungsfragebogen (SVF). Göttingen: Hogrefe.

Janke, W. \& Erdmann, G. (2002). SVF 78. Eine Kurzform des Stressverarbeitungsfragebogens SVF 120. Manual. Göttingen: Hogrefe.

Janke, W., \& Erdmannová, G. (2003). Strategie zvládání stresu - SVF 78. (Transl. J. Švancara) Praha: Testcentrum.

Kaiser, H. F., \& Dickman, K. (1959). Analytic determination of factors. American Psychologist, 14, 425430.

Krohne, H. W. (1989). Individual differences in coping. In M. Zeidner \& N. S. Endler (Eds.). Handbook of coping: theory, research, applications (pp. 381-409). New York, NY: Wiley.

Lazarus, R. S. (2006). Stress and emotion. A new synthesis. New York, NY: Springer.

Rubin, Z., Peplau, L. A., \& Salovey, P. (1993). Psychology and health. In DeRocco, M., Mancuso, T., \& Piland, S. (Eds). Psychology. (pp. 426-432). Boston, MA: Houghton Mufflin.

SPSS - Statistical Package for the Social Sciences (2005). Chicago, Ill.: SPSS Inc.

Weyers, P., Marcus, I., Reuter, M., \& Janke, W. (2005). Comparing two approaches for the assessment of coping: Part I. Psychometric properties and intercorrelations. Journal of Individual Differences, 26, 207-212. 